\title{
Ludovicus: Um estudo do Instituto Câmara Cascudo enquanto produto turístico da cidade do Natal (RN)
}

\author{
Ludovicus: a study by the Câmara Cascudo Institute while the tourism \\ product of the Natal City (RN, Brazil)
}

\section{Patrícia Daliany Araújo do Amaral, Andreia Candida dos Santos, Josineide Silva Monteiro, Mickaella de Fátima Medeiros, Tatiana Gehlen Marodin}

\begin{abstract}
RESUMO
O artigo tem como objeto de pesquisa o Ludovicus - Instituto Câmara Cascudo, local de produção artística, e que concentra a maioria das obras do folclorista Câmara Cascudo. $O$ trabalho propôs-se a estudar o espaço como atrativo turístico, abordando uma temática sobre o turismo atrelado à cultura como uma opção à necessidade de diversificar o segmento sol e mar, e ao fortalecimento de uma identidade cultural. Os procedimentos metodológicos envolveram uma pesquisa exploratória, que incluiu pesquisas bibliográficas, e de campo, tendo em vista que o trabalho teve como objetivo conhecer o prédio do Instituto, a sua gestão e infraestrutura. A pesquisa também contemplou a realização de entrevistas com gestores tanto do turismo quanto da cultura do estado do Rio Grande do Norte. Assim sendo, este trabalho analisa o instituto enquanto produto sustentável, assim como estuda a sua transformação em produto turístico para o turismo cultural da cidade de Natal e do Rio Grande do Norte. O resultado das pesquisas revelou a inexistência de ações práticas que valorizem a cultura local, de maneira a fortalecer o segmento do turismo cultural na localidade em estudo, posto que o Instituto é um equipamento pronto para receber a demanda, mas ele, por si só, não é suficiente para atrair um fluxo de turistas.
\end{abstract}

PALAVRAS-CHAVE: Turismo; Cultura; Câmara Cascudo; Instituto Ludovicus.

\section{ABSTRACT}

This paper has a research subject the Ludovicus - Câmara Cascudo Institute, the place where Camara Cascudo's production and most of his works can be found. The paper studies it as a touristic attraction, approaching a tourism theme connected to the culture as an option to the need of sun and sea tourism diversification and to the strengthen of a cultural identity. The method's procedures involved an exploratory research, that included bibliographic and field researches, once the paper had as objective to know the Institute's building, it's management and infrastructure. The paper also have interviews with State's tourism and culture managers. Therefore, this paper analyzes the Institute while sustainable product and studies it's transformation in touristic product for Rio Grande do Norte and Natal, for its cultural tourism. Research's results reinforced the absence of practical actions that valorize local culture in a way to strengthen cultural tourism segment at the studied place, because the Institute is a ready equipment for the request, but it alone is not enough to attract a flow of tourists.

KEYWORDS: Tourism; Culture; Câmara Cascudo; Ludovicus Institute. 


\section{Introdução}

Ao viajar, normalmente o turista tem como principal objetivo, entre outros motivos, a experiência de vivenciar novas culturas, o desfrute de seus momentos de lazer, ou mesmo o aprendizado ou aperfeiçoamento profissional. Mesmo quando não tem como foco central a questão cultural, ele acaba tendo um envolvimento com a mesma, pois a partir do momento no qual o indivíduo desloca-se de seu habitat com o intuito de conhecer novos lugares, ele passa a se socializar com modos de vida diferentes. Com isto, adquire novos conhecimentos, estabelece maiores condições de absorver comportamentos diversos, como também de influenciar outras pessoas. Assim, pode-se dizer que a cultura é uma das principais razões para a realização de viagens.

Pensando nesta questão, entende-se que, para a construção de um produto turístico atraente e sustentável, é preciso conservar os recursos naturais e os bens materiais e imateriais, bem como prepará-los para a exposição ao público. No caso dos bens culturais, isto só pode ser viabilizado através da participação efetiva na gestão cultural, e uma boa alternativa para tal são as parcerias, sejam elas realizadas com os setores público ou privado. Isto ocorre porque, para o turista ter essa vivência com a cultura e o patrimônio cultural, ele precisa encontrar lugares estruturados, bem conservados e valorizados pela comunidade local.

A cidade de Natal é o lugar onde nasceu uns dos personagens mais importantes da cultura brasileira, Luís da Câmara Cascudo, que foi estudioso da cultura nacional e deixou um valioso legado para o país. Em janeiro de 2010, foi aberta à visitação pública a casa onde ele viveu durante quarenta anos, agora na condição de Instituto. O Ludovicus - Instituto Câmara Cascudo, foi um dos principais laboratórios de sua produção artística, e atualmente concentra a maioria de suas obras.

No decorrer deste trabalho, será apresentado um levantamento sobre a vida e obra de Câmara Cascudo, assim como do Instituto Ludovicus, a fim de apresentar e analisar a sua infraestrutura, gestão, o acervo disposto aos visitantes, entre outras questões. Também são propostas ações com o objetivo de tornar o legado cultural de Câmara Cascudo, através do Instituto Ludovicus, um produto turístico sustentável para o turismo cultural na realidade estudada.

Diante do legado deixado por Câmara Cascudo para a cidade de Natal, destaca-se a importância do mesmo em tornar-se um patrimônio acessível à sociedade, para que haja um reconhecimento e valorização da memória cultural brasileira. Assim, coloca-se como problemática central desta pesquisa: como o legado cultural de Luis da Câmara Cascudo pode ser transformado em um conjunto de ações que tornem esse potencial um produto turístico sustentável? Para responder a esse questionamento, colocou-se como objetivo geral da pesquisa propor ações e tornar o legado cultural de Câmara Cascudo, através do Instituto Ludovicus, um produto turístico sustentável. Para que o mesmo fosse alcançado, foram elencados alguns objetivos específicos: levantar informações sobre a vida e obra de Câmara Cascudo e do Instituto Ludovicus, bem como sobre o local enquanto produto turístico; analisar a gestão do Instituto, assim como da infraestrutura física que o compõe; propor ações que busquem a inserção do objeto de estudo na atividade turística de forma ativa.

O presente trabalho justifica-se pela motivação de ser Câmara Cascudo o perso- 
nagem do RN mais conhecido nacional e internacionalmente e pelo valor cultural do Instituto Ludovicus, a fim deste ser desenvolvido como atrativo cultural para atividade turística de Natal. Para as autoras, a importância desse trabalho dá-se devido à oportunidade de conhecer melhor a questão cultural e desenvolvê-la atrelada ao turismo. Para a sociedade, serve como fortalecimento da identidade cultural da comunidade, já que Cascudo foi um dos mais importantes relatores da cultura potiguar, sendo assim um potencial contribuinte para a formação da identidade da população local. Nesse sentido, Pires (2001, p.102) afirma:

[...] a identidade cultural é o conjunto de caracteres próprios, e exclusivos de um corpo de conhecimentos, seus elementos individualizadores e identificadores, enfim o conjunto dos traços psicológicos, o modo de ser, de sentir e de agir de um grupo, que se reflete nas ações e na cultura material.

Também há a possibilidade de geração de renda e o reconhecimento do valor artístico para a atividade turística local. Academicamente, a importância dá-se devido à percepção para identidade turística e cultural. Reconhecendo a importância deste trabalho, tem-se a oportunidade de conhecer melhor a cultura, notadamente através de uma personalidade local, que tem sua importância em âmbito nacional e internacional.

Para a efetivação deste trabalho, a pesquisa adotada foi exploratória, uma vez que o trabalho teve como objetivo conhecer o prédio do Instituto, sua gestão e infraestrutura. Este método limita-se a definir os objetivos, buscando informações sobre o assunto estudado (BERVIAN; CERVO; SILVA, 2002), servindo para familiarizar-se com o fenômeno ou problema, tornando-o mais explícito. Para o planejamento desta pesquisa, foi utilizada a pesquisa bibliográfica e o estudo de campo. A pesquisa bibliográfica diz respeito a toda bibliografia publicada relacionada ao tema do estudo. Esta é a fase de levantamento de dados, considerada o primeiro passo para qualquer pesquisa científica é realizada com o intuito de reunir informações sobre o campo de interesse (LAKATOS; MARCONI, 2007). Para isso, foram desenvolvidas leituras bibliográficas sobre diversas áreas, como gestão, sustentabilidade, turismo, patrimônio cultural e a biografia de Câmara Cascudo.

A observação sobre o patrimônio artístico e cultural do espaço e de seu entorno, foi realizada através da pesquisa de campo. A coleta dos dados foi realizada no prédio do Instituto, bem como na Secretaria Estadual de Turismo e na Secretaria Municipal de Cultura, onde foram realizadas entrevistas. A pesquisa buscou informações sobre como a atividade turística é vista e analisada pelos profissionais do turismo, são as potencialidades, como o turismo cultural é desenvolvido e se existe uma estrutura de apoio para o Instituto Câmara Cascudo se posiciona como atrativo turístico.

O público participante da pesquisa incluiu representantes de órgãos gestores do turismo, do Instituto, assim como dos órgãos fomentadores da cultura no Rio Grande do Norte. Os entrevistados foram escolhidos por serem tomadores de decisões e planejadores dos setores do turismo e da cultura na localidade em estudo, sendo eles: Daliana Cascudo (diretora administrativa do Ludovicus), Paulo Eduardo Pereira da Silva (colaborador do Instituto), Jurema Márcia Dantas da Silva (conselheira do Conselho Nacional de Turismo, representante do Fórum Nacional dos Cursos Superiores de Turismo e Hotelaria, profissional atuante no setor turístico do $\mathrm{RN})$, Carmen Vera de Lucena 
(coordenadora técnica da Secretaria de Estado de Turismo do RN - SETUR), Marilene Brito (então subcoordenadora do Patrimônio Histórico e Cultural da SETUR) e Henrique Fontes (teatrólogo, ator e dramaturgo que desenvolveu um trabalho sobre o universo de Cascudo). As entrevistas permitiram construir gradativamente a compreensão a respeito da imagem e atuação do equipamento turístico.

\section{Pensando no turismo cultural e no seu consumidor}

\section{Um pouco do segmento cultural no turismo}

Com o surgimento dos estudos envolvendo os turistas e os classificando a partir de perfis, foram sendo desenvolvidas simultaneamente as tipologias do turismo. Smith mapeou cinco tipos da atividade, na qual dentre elas já existia o turismo cultural, que segundo a mesma "consiste em conhecer lugares pitorescos com "cor local", comer "comidas típicas" e ver manifestações folclóricas" (SMITH, 1989 apud BARRETTO, 2007). Atualmente, o turismo cultural compreende uma variedade de atividades bem além dos três atos colocados pela autora, mais focados no conhecimento e valorização do patrimônio a que se refere, e menos desprendidos dos reflexos do universo contemporâneo.

O surgimento do turismo cultural foi ofuscado durante aproximadamente 20 anos pelo turismo de massa, que durante algum tempo mostrou-se um instrumento de crescimento econômico, gerador de emprego e renda, mas que teve essa imagem invertida em razão da falta de compromisso, geralmente de empresas multinacionais, "[...] com a problemática local, com as questões ambientais e com o retorno econômico para a população" (BARRETTO, 2007, p.83).

Assim, esta segmentação do turismo veio ressurgir somente nas últimas décadas do século XX, juntamente com outras abordagens, como aborda Santana (2009, p.124): "questões como a depredação do meio ambiente, o resgate da diversidade e especialmente do que se considera patrimônio cultural, a ecologia e o 'orgânico' são, na atualidade, aspectos consubstanciais a vida cotidiana [...]". Desta forma, o turismo cultural veio como um novo nicho para o mercado globalizado, apresentando uma demanda específica, atraída pelo cotidiano de outras culturas, em busca de experiências autênticas, enriquecimento educacional, e até da reconstrução de uma nova identidade, dispostos em uma paisagem cultural, dentro do turismo.

A exploração de atrações culturais através do turismo resultou no crescimento deste segmento. Segundo Santana (2009), quando essa exploração ocorre de forma planejada com base nos preceitos do turismo responsável, promove o amadurecimento da consciência de proteção da população, a geração de renda complementar, a construção de infraestrutura (transportes, vias de comunicação), entre outros benefícios. Já ao turista, todos esses aspectos atrelados ao equipamento poderão oferecer experiências únicas, satisfatórias e marcantes. É preciso também reconhecer e enfatizar o papel educativo do turismo cultural na sociedade, já que este se utiliza de um equipamento a fim de possibilitar desdobramentos importantes no público apreciador, desde a interação do indivíduo com o ambiente, até a reconstrução de visões e conhecimentos definidos. Segundo Dias (2006), é pelo qual se amplia e se consolida um conhecimento, o qual culmina em um contato direto do individuo com uma atividade cultural. 
Através deste conhecimento adquirido, o homem pôde entender os fatos históricos que permitiram o surgimento de novos povos ou o desaparecimento de outros, conhecer a história das localidades e de seus antecedentes, as particularidades de grupos que vivem isolados, etc. O turismo cultural não está apenas relacionado à contemplação, mas também aos conhecimentos, atrelados ao desfrute do lazer e descanso, já que se está de férias.

Entendendo esse binômio turismo e cultura, cria-se a segmentação denominada turismo cultural, que segundo definição desenvolvida pelo Ministério do Turismo juntamente com o Ministério da Cultura e o Instituto do Patrimônio Histórico e Artístico Nacional - IPHAN, compreende "[...] as atividades turísticas relacionadas à vivência do conjunto de elementos significativos do patrimônio histórico e cultural e dos eventos culturais, valorizando e promovendo os bens materiais e imateriais da cultura" (BRASIL, 2007, p.19). Assim, faz-se necessária uma maior compreensão deste segmento, que é considerado um dos principais mercados do turismo, devido ao fato de poder estar associado a outras atividades turísticas e de incorporar várias formas e espaços culturais, a exemplo de museus, galerias, eventos culturais, festivais, festas, arquiteturas, sítios históricos, apresentações artísticas e etc, conforme definição de Dias (2006).

A questão é que a maneira como a atividade foi implantada em alguns lugares resultou em danos ao patrimônio, assim como desrespeito à identidade cultural local em função da imposição de novos padrões. Desta forma, observou-se a necessidade de implantação de ações conjuntas entre os setores de turismo e cultura, para se obter o meIhor aproveitamento da atividade turística (BRASIL, 2008, p. 15). Assim sendo, estas parcerias são importantes para proteção e valorização do patrimônio cultural e da identidade cultural local.

Além disso, o segmento em questão não depende de condições climáticas, para desenvolver-se, como é o caso do turismo de sol e praia ou de aventura, o que possibilita a sua realização ao longo do ano, sendo uma estratégia para melhorar a distribuição do fluxo turístico e a ocupação nos período conhecido como baixa estação. Como se pode ver, o turismo cultural, sendo compreendido em sua totalidade, deve ser visto como alternativa para o desenvolvimento de um turismo sustentável e agregador de valores para os outros segmentos, assim como para o fortalecimento da identidade cultural da comunidade.

\section{O consumidor cultural}

Por volta de 1970, falava-se do turista de uma forma generalizada, como se todos que viajassem apresentassem os mesmos interesses e finalidades. Porém, a partir da observação sobre as motivações dos usuários e elementos padrões do processo da viagem, como a duração, frequência, o transporte utilizado para o deslocamento, os atrativos mais visitados, a forma que se apresentavam (em grupos, família, individualmente) pesquisadores perceberam a existência de variadas formas de turismo, e, assim, turistas com diversos gostos. A partir de então, foram iniciados o mapeamento e caracterização das tipologias do turismo e seu principal alvo, o turista.

O turista cultural é levado pela significação dos processos de vivência, como mos- 
tra Barretto (2007, p.81): "Intelectuais, profissionais liberais, gerentes, trabalhadores independentes (white collars), ao contrário, procuram propostas culturais, a moderna peregrinação a locais significativos [...]". Os turistas motivados a visitar atrativos culturais valorizam a cultura em toda a sua complexidade e particularidade, buscam experiências, fatos históricos e elementos culturais comuns a um grupo ou comunidade. Segundo pesquisa realizada pelo México, existem dois tipos de turista: aqueles com interesse específico na cultura e aqueles com interesse ocasional. Os primeiros são os que desejam aprofundarse na compreensão das culturas visitadas e se deslocam especialmente para esse fim, já o segundo relacionam-se com a cultura apenas como opção de lazer, muitas vezes visitam algum atrativo cultural, mesmo não tendo se deslocado para este fim México (200apud BRASIL, 2008).

Segundo o ICOMOS/OMT (1993 apud DIAS, 2006) os turistas mais experientes preferem fazer contato com a cultura local. Esta é a principal motivação de sua viagem. Estes turistas têm um perfil particular, estão preocupados com o meio ambiente, são politicamente informados, interessados por culturas diferentes, viajam com frequência, são bem educados e aparentam ser amigáveis nos encontros com o estrangeiro. Existem também os que, ao viajar, não buscam o contato com a cultura como primeira opção. São chamados de clientes indiretos do turismo cultural, buscam conhecimento, mas não o cientifico, apenas o que permite entender o que está sendo apresentado. Limitado apenas ao momento da visita (TAVALERA, 2003 apud DIAS, 2006).

\section{Apresentando Câmara Cascudo e o Instituto Ludovicus}

\section{Mestre Cascudo: vida e obra}

Luis da Câmara Cascudo nasceu em 30 de dezembro de 1898 na Rua Senador José Bonifacio, mais conhecida como Rua das Virgens, no bairro da Ribeira, cidade do Natal. Teve uma infância bem restrita, não foi garoto de subir em árvores, de correr, em virtude de problemas de saúde, por isso dizia não ter recordações dessa fase. Porém, recordava-se que adorava ouvir as amas contarem histórias e de ir a espetáculos populares. E desse gosto pelo cotidiano e pelo normal, que ele atribuiu o surgimento das ideias para seus livros (LYRA, 1999).

Aos dezessete anos, terminou o ginasial e aos 18 entrou para Faculdade de Medicina (Bahia e Rio de Janeiro), cursando apenas até o quarto período. Quando morou no Rio de Janeiro trabalhou como oficial de gabinete do Ministro da Justiça, Joaquim Ferreira Chaves. Ao relatar esse tempo, Cascudo dizia que era um rapaz que usava "polainas, monóculo [...] encantado com a vida" (LYRA, 1999, p.39). No quarto período de Medicina, abandonou o curso por não ter dinheiro para montar um laboratório, então mudou para o curso de Direito em Recife, formando-se em 1928 (LYRA, 1999). No mesmo ano, assumiu como professor interino do antigo Atheneu Norte Riograndense, função essa que começara desde cedo em colégios e cursos particulares, e seguiu até a universidade. Destacou-se por ser um professor inovador, saindo dos conteúdos programados dos livros de sala de aula e por sua erudição, memória e conhecimento. Suas aulas chamavam a atenção dos alunos de outras classes, que eram atraídos à porta da sala, onde Cascudo expunha as palavras, com saber e emoção (AMERICA, 2008). Logo após esse início como professor, casou-se, em 1929, com a jovem, Dáhlia Freire, e tiveram dois fiIhos, Fernando Luis e Anna Maria. Dáhlia sabia da sua importância na criação do escritor, 
dizia que esposa de escritor tem que se doar e renunciar (Ibid. 1999). Foram 57 anos de casamento (LIMA, 1998).

No ano de 1941, fundou a Sociedade Brasileira de Folclore, em Natal, na sua própria casa. Dentre os principais trabalhos desenvolvidos pela associação, está a fundação da Federação dos Folguedos Tradicionais, a representação nos Congressos de Folclore de Oslo e de Estocolmo, a publicação de uma classificação do conto popular, a campanha de valorização das bonecas de pano, e a proteção ao artesanato. O folclorista baiano Édison Carneiro diz que a preservação de toda a riqueza dos folguedos populares da cidade do Natal, deve-se ao trabalho da Sociedade Brasileira de Folclore (AMERICO, 2008).

A Sociedade Brasileira de Folclore tinha, em seu fundador, sua grande força, "existira em função dele, de seu entusiasmo criador, de sua tenacidade" (COSTA, 2008, p.84). A maioria de suas pesquisas foi registrada em suas obras como Vaqueiros e Cantadores (1939), Geografia dos Mitos Brasileiros (1947), Anúbis e outros Ensaios (1951), Antropologia do Folclore Brasileiro (1944), Literatura Oral, História da Literatura Brasileira (1952), Folclore do Brasil (1967), o Dicionário do Folclore Brasileiro (1954). Este último é seu livro mais completo, onde se encontra sua personalidade e sua obra (COSTA, 2008).

Há um destaque para o Dicionário do Folclore Brasileiro, que se tornou a primeira compilação acadêmica sobre o folclore, "[...] não é trabalho para ser feito por um só homem, mas por uma universidade. Cascudo fez tudo sozinho, sem sair de Natal' (LIMA, 1998, p.12). Para Rabaçal a obra é uma:

[...] fonte de consulta indispensável a todos aqueles que querem conhecer, que querem estudar a chamada cultura brasileira, a cultura popular brasileira, aquela cultura espontânea, que não advêm de pressões de nenhuma natureza, mas que brota, que advem como o próprio homem na sua formação (apud LYRA, 1999, p.22).

Seus estudos sobre a etnografia surgiram do grande interesse humano que Cascudo tinha em pesquisar as coisas controvertidas (LYRA, 1999). Na sua trajetória como escritor, ficou conhecido por gostar de trabalhar até a madrugada, fato esse que marcou na cidade de Natal, onde no período da II Guerra Mundial, sua biblioteca era a única iluminada durante o black-out, mediante autorização do comando militar. Nos seus mais de 150 livros e ensaios, ficam evidentes suas pesquisas sobre etnografia e folclore e a predileção por história, geografia e biografia. O folclorista recebeu inúmeras distinções, condecorações, títulos, honrarias que o consagram cidadão do mundo. Em 1977, recebeu o Prêmio Juca Pato, como o intelectual do ano, pelo livro Antropologia da Alimentação Brasileira. Para o amigo Carlos Lyra (1999) o Rio Grande do Norte, possuía dois grandes monumentos: um a Fortaleza do Reis Magos e outro Luis da Câmara Cascudo. Seus trabalhos de pesquisas o tornaram conhecido em todo o mundo. Zila Mamede costumava fazer uma colocação que pode resumir todo o seu conhecimento de mundo, algo que diria "independente do assunto pergunte a Cascudo". É considerado, ainda, um dos últimos enciclopedistas. Homem de grande sabedoria, dominava vários idiomas como francês, italiano, espanhol, inglês e alemão; e ainda o latim e o grego (LYRA, 1999). 


\section{Instituto Ludovicus}

O Ludovicus - Instituto Câmara Cascudo - tem como principal objetivo a divulgação e preservação do patrimônio cultural de Luis da Câmara Cascudo. Está situado no bairro da Cidade Alta, na cidade do Natal - RN. O nome Ludovicus significa Luis em latim, e apresenta um valor sentimental à família de Cascudo. A casa sempre foi um local de visitação, e após a morte de Cascudo, as pessoas sempre pediam para conhecê-la, pedido sempre concedido pelos familiares.

Assim, o Instituto foi nomeado e criado oficialmente em 2007 por sua família, tendo na presidência sua filha Anna Maria e funcionando na casa onde viveu durante quase 40 anos e produziu a maioria de suas obras. O prédio pertencera antes ao seu sogro, mas com o falecimento do mesmo, Câmara Cascudo comprou-o de sua sogra Dona Maria Leopoldina Vieira Freire e lá viveu até o fim dos seus dias. O edifício, que fora tombado desde 1990 em nível estadual, foi restaurado, e, por si só, pode ser considerado uma aula de história e cultura brasileira. Cada ambiente apresenta particularidades, impregnados por lembranças familiares.

$\mathrm{Na}$ sala, é possível visualizar fotografias de amigos ilustres. Na biblioteca, 10 mil volumes de obras literárias (tanto brasileiras como internacionais), além de 15 mil correspondências, 2 mil periódicos, 1.200 plaquetas, 2.000 fotografias, 1.000 artigos de jornal, diversos documentos, e em suas paredes autógrafos de visitas ilustres da casa. A sala de visitas conta com mobiliário de época, pinacoteca, coleções de arte popular e estrangeira, peças de arte sacra, etnografia africana e indígena, além de comendas, que também compõem o acervo. O prédio possui também uma loja que disponibiliza obras do autor e estudos, livros raros, dentre outros produtos interessantes sobre o universo de Cascudo.

\section{Analisando o discurso dos profissionais sobre as possibilidades do turismo cultural e do Instituto Ludovicus}

\section{Turismo sobre a ótica dos profissionais do poder público e da iniciativa privada}

Através da realização das entrevistas com os profissionais do turismo e cultura que fortemente atuam nos setores do turismo e da cultura no estado, principalmente na cidade do Natal, foi possível observar diversos pontos pertinentes à pesquisa.

Compreende-se que o turismo cultural na cidade do Natal ainda é incipiente, mesmo diante da oferta de atrativos culturais existentes. A atividade turística da cidade de Natal encontra-se arraigada no segmento de sol e mar, como foi citado por todos os entrevistados, o que torna urgente a sua diversificação. Conforme Dias (2006), o desenvolvimento do turismo cultural é importante, posto que o turista que viaja motivado pela cultura gera o aumento no desenvolvimento de outros setores, como a hotelaria, gastronomia e serviços de lazer e recreação. A exploração desse segmento, segundo Santana (2009), bem planejada, ainda proporciona o aumento da consciência de proteção da população, a construção de infraestrutura (transportes, vias de comunicação), dentre outros aspectos, os quais poderão oferecer experiências únicas, satisfatórias e marcantes. 
Segundo Carmen Vera, coordenadora técnica da SETUR, existem as melhores expectativas possíveis com relação ao desenvolvimento do turismo, de maneira geral, na cidade, principalmente em relação ao turismo doméstico. A mesma aponta o clima da cidade, a hospitalidade e os atrativos naturais como suas principais potencialidades, apontando a necessidade de agregar o turismo cultural. Com relação ao Instituto Ludovicus, a entrevistada considera-o um atrativo turístico, mas que precisa se transformar em um produto comercial.

Marilene de Brito, que na época da pesquisa atuava enquanto subcoordenadora do Patrimônio Histórico e Cultural da SETUR, apontou as iniciativas que fazem parte do Plano de Desenvolvimento Integrado do Turismo Sustentável - PDITS - como as principais ações para recuperar e estrutura o patrimônio histórico-cultural do Pólo Costa das Dunas (do qual Natal é município integrante). Dentre estas ações, destacase o fortalecimento do turismo cultural, diversificando a oferta turística disponível nos próximos anos. Essas ações serão realizadas através do Programa de Desenvolvimento do Turismo no Nordeste - PRODETUR/NE - que é financiado com os recursos do Banco Interamericano de Desenvolvimento - BID - e têm o Banco Nordeste como órgão executor. As ações previstas que estão relacionadas ao desenvolvimento do segmento do turismo cultural envolvem aspectos como a implantação do Museu da Rampa e Memorial do Aviador, reforma e ampliação do Centro de Turismo e a elaboração e implantação do Projeto Executivo de Reabilitação Urbana do Corredor Cultural de Natal, bem como do Plano de Interpretação Integral do Corredor Cultural de Natal e elaboração do projeto e implantação do Centro de Gestão Integrada do Corredor Cultural de Natal, entre outras questões.

Em função das questões apresentadas, pode-se salientar a importância da realização dos projetos que envolvem o Corredor Cultural, que ao serem desenvolvidos, deverão fortalecer e estimular o desenvolvimento do turismo cultural na cidade, e fomentar atividades artísticas, tendo em vista a concentração destas no mesmo espaço pertencente ao corredor, e uma maior oferta de entretenimento para o público local. Em contrapartida sabe-se também que o projeto do corredor cultural em Natal, no qual está inserido o Instituto Ludovicus, foi reelaborado diversas vezes em um período de aproximadamente 20 anos, e que até então nenhuma ação referente à execução deste foi realizada.

A entrevistada avalia como inconsistente a estrutura de apoio ao turismo cultural no estado, e isso se dá como consequência da falta de políticas de apoio ao segmento. Para que existam as políticas, faz-se necessária a articulação entre agentes do turismo do setor cultural e o reconhecimento do segmento como uma nova opção de incremento da oferta turística e de combate à sazonalidade. Como alternativa ao exposto, a entrevistada informou que o Instituto atende a essa necessidade de diversificar a oferta turística, por já ser um atrativo ímpar. E que o diferencial está na valorização da personalidade potiguar, de seu ícone. Porém, ela colocou que a questão do nome Ludovicus dificultar a divulgação do equipamento, tornando-se bem mais prático apenas Casa de Câmara Cascudo, ao invés de Instituto Ludovicus.

A professora Jurema Dantas, do Conselho Nacional de Turismo e do Conselho 
Estadual de Turismo - CONETUR - e ainda do Conselho de Turismo do Polo Costa das Dunas vê o turismo no estado com a característica de "familiaridade". Segundo ela, as pessoas que visitam Natal geralmente já estiveram outras vezes na cidade, apreciam as belezas naturais, a hospitalidade, mas necessitam de novas possibilidades de visitação dentro do destino Natal, fortalecendo assim a afirmação de que "são raros os tipos puros de turismo, e de turistas (PEARCE,1982, apud SANTANA, 2009). Suas expectativas para o desenvolvimento do turismo no estado são excelentes, devido às potencialidades que possui, os recursos naturais, a cultura, os museus, que apesar de se encontrarem com uma estrutura precária detêm interessantes acervos e os novos produtos que surgem originados de diferentes segmentações. Todavia, reforça também o fato de não haver produtos com uma estrutura razoável que atenda ao visitante.

Jurema Dantas salientou que pesquisas apontam o turismo cultural como o diferencial nos países de primeiro mundo, destacando a necessidade de preparar e valorizar os potenciais culturais de uma região. Citou a atuação do Instituto Ludovicus como exemplo de um produto estruturado, mas ainda não constituído como atrativo, porém, se bem trabalhado, poderá trazer uma série de benefícios, como o conhecimento de uma cultura e a contribuição para a captação de mais turistas. A mesma também reforçou as ações do PDTIS, já citadas anteriormente.

Observa-se no discurso dos entrevistados que existe uma compreensão sobre o segmento turismo cultural, mas que, na prática, ele ainda não é trabalhado na realidade local. Sugere-se pensar, ao implantar o Museu da Rampa e Memorial do Aviador, assim como o Projeto Executivo de Reabilitação Urbana do Corredor Cultural de Natal, como esses novos atrativos serão trabalhados. Por diversas vezes, acredita-se ser este o gargalo no turismo: existe o produto, mas não há divulgação, estrutura de estacionamento, pessoas qualificadas para atendimento ao público, entre outras deficiências. Questões como essas dificulta, o acesso da demanda ao atrativo.

Daliana Cascudo, neta de Câmara Cascudo e diretora administrativa do Instituto, entende que o turismo cultural serve para mostrar o que do ponto de vista histórico, suas personalidades, fatos importantes e suas manifestações culturais. Como o principal benefício da segmentação, apontou a questão educacional. Segundo Dias (2006), é através desse contato direto do indivíduo com seu interesse particular, que pode ser um monumento, ou um artesanato ou até uma dança, que se amplia e constrói um conhecimento. A entrevistada também citou a valorização da identidade cultural e a possibilidade de melhoria na condição de vida da comunidade envolvida na sua realização.

Segundo Daliana, não existe turismo cultural em Natal, e isso se concretiza pela inexistência de uma infraestrutura de apoio para o segmento. Contudo, a expectativa que o turismo do RN consiga vender o nome Câmara Cascudo, seus valores literários e também a temática da presença dos americanos na cidade do Natal no período da Segunda Guerra Mundial, potencialidades turísticas que ela aponta na cidade do Natal.

A entrevistada informou que a ideia de representar Câmara Cascudo surgiu da ne- 
cessidade de diversificar o turismo de sol e mar. Assim, a família deu início ao trabalho para preparar a casa onde ele morou, transformando-a no Instituto. Para ela, o diferencial do atrativo turístico é ter sido o local onde Cascudo viveu por mais de 40 anos, local de produção de sua obra. Daliana apontou que, apesar do equipamento estar pronto para ser trabalhado como um produto turístico, ainda falta apoio externo, como divulgação em postos de informação turística, placas de sinalização turística, infraestrutura externa e a inclusão do Instituto nos roteiros comercializados, e vê como maior desafio a divulgação do produto para chegar até o público interessado.

Paulo Eduardo, monitor do Instituto Câmara Cascudo, reforçou ter o turismo local o perfil de sol e mar, e que isto se dá em função da falta de divulgação por parte do poder público, e que deveria haver mais iniciativas relacionadas ao turismo cultural. O entrevistado citou como potencialidade para o turismo em Natal o bairro da Ribeira, a Praia da Redinha e os bairros de Petrópolis e Tirol. Para ele, turismo cultural é um movimento de grupos à procura de marcas ou símbolos de outros povos, a busca pela trajetória de outras culturas. Conforme Barretto (2007, p. 81), esses grupos "[...] procuram propostas culturais, a moderna peregrinação a locais significativos [...]".

O diretor artístico e educativo do Espaço Cultural Casa da Ribeira, Henrique Fontes, reconhece o turismo como a principal atividade econômica do estado, e as praias e belezas naturais como principais atrativos da cidade, mas percebe o desejo expresso por parte dos turistas em vivenciar os hábitos locais. Tal percepção deve-se também ao fato deste manter um contato cotidiano com os turistas, já que a Casa da Ribeira (instituição cultural tida como referência na cidade do Natal) é aberta à visitação durante toda a semana. O entrevistado cita o bairro das Rocas como potencial turístico, por ser um território rico em manifestações e diversidade cultural, e avalia a gestão e atuação do Turismo Cultural no RN como precária e deficiente quando se trata dos quesitos divulgação, informação e pessoal qualificado para o atendimento, destacando ainda a falta de articulação entre os setores.

Ainda assim, reconhece o poder do turismo cultural, quando bem executado, em proporcionar momentos de encantamentos aos visitantes, o compromisso do segmento com a sustentabilidade e o destaque para o papel educativo que desempenha, construindo relações e derrubando preconceitos. O artista possui intimidade com a "casa e obra de Câmara Cascudo", pois há algum tempo estuda e possui como inspiração esse universo. Para Henrique Fontes, Cascudo é a verdadeira representação do povo potiguar, exemplo de inteligência emocional, e sua casa traz memórias curiosas, boa estrutura física, e a disponibilidade dos gestores do Instituto a novas propostas de exposição e atividades.

\section{Analisando o Instituto: gestão e infraestrutura}

A criação do Instituto Câmara Cascudo partiu da filha do pesquisador, Anna Maria Cascudo, atualmente Presidente do equipamento, e da neta Daliana Cascudo, Diretora Administrativa. Em entrevista, Daliana informou que a ideia para instalação do Instituto surgiu como uma maneira de representá-lo a altura de Câmara Cascudo, e para isso a família teve que se desfazer de parte do patrimônio pessoal para investir na restauração e recuperação do mobiliário e da casa, que no período de 2005 estava com o telhado comprometido devido uma infestação de cupins, o que demandou um gasto financeiro. 
Os recursos que mantêm o Instituto são gerados pela venda dos produtos comercializados na loja lá localizada. A taxa cobrada para visitação e os direitos autorais referentes à venda dos livros do pesquisador, que iriam para sua filha Anna Maria Cascudo, são revertidos para o Instituto. Quanto à gestão do equipamento, a Diretora Administrativa Daliana Cascudo expõe algumas dificuldades da gestão no que diz respeito ao poder público, que poderia dar um apoio maior para fortalecer o espaço enquanto produto turístico, citando como exemplo a solicitação das placas de sinalização turística, as quais poderiam permitir que os ônibus turísticos estacionassem em frente ao prédio. Trata-se de uma solicitação ainda não atendida, dificultando a visitação de grupos de turistas. Há também uma deficiência em relação à divulgação do produto dentro do próprio trade turístico. Esta fala foi reforçada quando um empresário do ramo do turismo receptivo expôs em reunião do Conselho de Turismo do Polo Costa das Dunas, que tem conhecimento do atrativo, mas que infelizmente não leva turistas para visitá-lo devido à falta de estacionamento.

Quanto à apresentação dos objetos no Instituto, trabalha-se sempre de forma temática. Por possuir um grande número de peças que fazem parte do acervo de artesanato popular e estrangeiro, comendas, peças de arte sacra, etnografia africana e indígena, periodicamente é realizada a renovação dessas exposições, o que possibilita que a cada visita seja visto algo novo. Todos os móveis da casa são os mesmos utilizados por Cascudo e família. Até mesmo a forma de organizá-los espacialmente na casa foi mantida. Como dito pela sua neta Daliana, o diferencial do Instituto é o fato de representar a memória de Câmara Cascudo, o ambiente em si traz a memória do objeto, que guarda a memória de seu dono.

A única alteração realizada na estrutura física do prédio foi a construção de um anexo, o pavilhão Dáhlia Freire Cascudo, construído com o intuito de guardar o acervo da biblioteca com todos os cuidados necessários para sua conservação. Este pavilhão também abriga um auditório com capacidade para 40 pessoas, que serve para realização de eventos culturais. O acervo da biblioteca, após a morte de Cascudo, foi doado à Fundação José Augusto, que o remanejou para o Memorial Câmara Cascudo. Com a criação do Instituto, o mesmo foi devolvido aos cuidados da família. Neste acervo, encontram-se as correspondências que Cascudo mantinha com pessoas de diversas partes do mundo, as quais estão passando por um processo de digitalização.

O Instituto encontra-se bem equipado para receber os visitantes. O prédio conta com uma boa estrutura física de apoio ao turista, com guarda volumes, lanchonete e banheiros. O prédio conta com acessibilidade, para facilitar a entrada de pessoas com necessidades especiais, além da entrada parte frontal do prédio que é uma escada, na lateral existe outra entrada que da para duas rampas que permitem livre acesso a boa parte do Instituto.

Já a visitação dentro da casa em alguns cômodos torna-se difícil devido à organização dos móveis. Acredita-se que pode haver uma nova arrumação, com vistas a facilitar a locomoção do visitante. Foi necessário adquirir um terreno localizado na lateral do Instituto, o qual estava abandonado e gerando insegurança. Com isso, foi possível equipar o local para receber as pessoas com deficiência, pois é por ali que ocorre a entrada com acessibilidade.

O terreno trata-se de um espaço amplo, o qual daria para fazer em uma parte estacionamento e em outro um espaço para entretenimento, como por exemplo, um café. 
Daliana Cascudo informou que já existe este desejo, mas que é algo ainda muito incipiente e para um futuro ainda distante devido a outras prioridades do Instituto, como a criação de um banco de dados que contenha informações sobre o acervo da biblioteca, para consulta.

O Instituto é um local onde Câmara Cascudo é apresentado cordialmente, através da memória do objeto, suas obras e toda uma vida de pesquisas etnográficas, por isso diante de tamanho legado deixado por Câmara Cascudo para a cidade de Natal, destacase a importância do mesmo em tornar-se um patrimônio acessível à sociedade, para que haja um reconhecimento e valorização da memória cultural brasileira.

\section{Propostas a serem pensadas para o equipamento turístico}

Conforme mencionam os profissionais entrevistados, as principais barreiras encontradas para a atuação do Ludovicus, enquanto equipamento turístico, são a inexistência de um estacionamento, assim como a falta de sinalização turística. Neste sentido, propõese conceder permanentemente duas vagas para ônibus turísticos em frente ao Instituto, que inclusive leva o nome de Av. Câmara Cascudo, bem como liberar diariamente estacionamento no quarteirão que o circunda durante períodos que não choquem com os "horários de pico" do comércio natalense. Como o mesmo está situado em uma área comercial, tornaria o acesso ao Instituto mais viável e não atrapalharia o trânsito, já que estaria utilizando-se de uma via larga com quatro faixas, respeitando o comportamento do fluxo de transporte urbano.

Também é sugerido sinalizar o equipamento com placas e simbologias, assim como também o seu entorno, que compreende os bairros da Ribeira e Cidade Alta. Trata-se de uma ação que envolve orientação ao turista e visitante local, tão necessária ao Instituto quanto as estratégias de acesso.

As ações anteriormente citadas devem ser executadas envolvendo as instâncias culturais governamentais (Fundação Cultural Capitania das Artes -FUNCARTE e Fundação José Augusto -FJA), já que se trata da manipulação de espaços públicos, em conjunto com a SEMURB (Secretaria Municipal de Meio Ambiente e Urbanização).

A falta de apoio externa citada pela diretora administrativa do Ludovicus, foi também sentida no decorrer das entrevistas realizadas. Vê se que há um reconhecimento do legado cultural de Câmara Cascudo, mas ao que parece existe certo receio por parte do trade turístico em apostar no equipamento enquanto atividade de negócios, portanto faz se fundamental que o Instituto seja incluído na Atividade Turística de forma ativa o mais breve possível, processo esse que pode ocorrer inicialmente através parceria com empresas do turismo, e a contrapartida de seus serviços.

Para que o Instituto Ludovicus seja bem promovido na cidade e no RN é preciso que ele esteja ativo na mídia local, que se faça conhecido da sociedade. Inserir o Instituto na rede virtual e em mídias sociais é uma forma barata e funcional de divulgar as atividades do equipamento, e quando alimentadas, essas ferramentas podem se tornar fomentadores do Universo de Câmara Cascudo e do turismo cultural.

Quando o turismo é trabalhado de forma planejada, ocorre um desenvolvimento local da área e da sociedade atuante. Tendo em vista a paixão que o mestre Cascudo 
possuía pela educação, e os benefícios gerados por esta, pensou-se na possibilidade de implantação de um programa educacional. O mesmo poderia disponibilizar o acervo bibliotecário do Instituto, ou parte dele, a profissionais e estudantes universitários com fins de pesquisa ou trabalho acadêmico, serviço este realizado sob controle de cadastro, tanto das obras, como dos usuários, tornando-se assim instrumento de fomento à pesquisa e à educação cultural.

Propõe-se construir uma programação planejada semestralmente como uma atitude indispensável ao bom andamento do Ludovicus. Através de exposições e apresentações, o mesmo tornará a sua atividade mais dinamizada, e assim mais prazerosa na interação com o público apreciador.

\section{Conclusões}

Câmara Cascudo foi um homem além do seu tempo. Correspondia-se com intelectuais do mundo. Estudioso da cultura potiguar, principalmente em suas manifestações populares, isto por si só é motivo para estudá-lo. Seu amor por Natal, sua cidade, está presente em seus escritos e falas, o que o fez conhecido por ser um provinciano incurável, por colecionar crepúsculos e valorizar os talentos populares (as apresentações folclóricas). Sentimentos estes que devem ser trabalhados na população local, na busca pela criação de uma identidade cultural que torne possível o fortalecimento das atividades voltadas para valorização dessa cultura. Diante do exposto, Câmara Cascudo é, e deve continuar sendo estudado, por toda sua contribuição para a formação do saber, não apenas o conhecimento científico, como também o empírico.

O Instituto Ludovicus, conforme análise realizada nesta pesquisa, já é um produto turístico pronto para receber a demanda de visitantes. A infraestrutura e os acessos com acessibilidade são satisfatórios. Portanto, espera-se que a implantação do corredor cultural de Natal, traga melhorias no que diz respeito à infraestrutura externa, como placa de sinalização turística, placa de estacionamento e até a própria viabilização de locais para estacionamento de ônibus turísticos.

Contudo, foi observado que ainda se trata de um produto isolado, e que se faz necessário que o segmento do turismo cultural seja planejado e realizado na cidade do $\mathrm{Na}$ tal, de maneira que o equipamento possa ser fortalecido. Em todas as falas dos entrevistados, foi unânime a necessidade de diversificar o turismo de sol e mar, que é o carrochefe da atividade turística desenvolvida na localidade em estudo.

A gestão do Instituto busca de todas as maneira consolidar esta parceria cultura e turismo, mas tem se deparado com falta de apoio, inclusive do poder público, agente importante nestas questões. Como se sabe, há uma necessidade do trabalho em parceria, com a iniciativa privada, poder público e comunidade local, é assim que se deve buscar efetivá-la, com vistas ao desenvolvimento de uma atividade sustentável.

Para efetivar ações que tornem o legado de Câmara Cascudo através do Ludovicus um produto sustentável, faz-se necessária a realização das demais ações que fortalecem o corredor cultural e o turismo cultural de modo geral. De nada adianta apresentar possibilidades de fomento do Instituto e o seu entorno, sem permitir a viabilidade do mesmo.

A presente pesquisa reforça a questão da falta de interesse do poder público em 
fomentar iniciativas para aumento da consciência e valorização da cultura. E também mostra que ainda há um longo caminho a ser trabalhado, para que o segmento do turismo cultural se torne realidade no estado. O fator positivo percebido, é que estas são medidas simples, porém dependentes da atuação de pessoal capacitado, e que possuam uma visão critica. Pois em alguns momentos têm-se a impressão que todos estão engessados numa zona de conforto, sabendo o que se deve fazer, mas sem atitude para começar. Fica demonstrado que já existe uma conscientização bem maior com relação à necessidade de diversificar a oferta de sol e mar, e que para isso o mais indicado seria o turismo cultural.

Diante do exposto, verifica-se a urgência em desenvolver estratégias bem planejadas e articuladas para o fortalecimento de uma identidade cultural. E que não seja apenas a família de Câmara Cascudo a preservar a sua memória, mas que a população seja despertada para a sua importância.

\section{Referências bibliográficas}

BARRETTO, M. Cultura e turismo: discussões contemporâneas. Campinas: Papirus, 2007.

BERVIAN, P.A.; CERVO, A.L.; SILVA, R. Metodologia científica. 6 ed. São Paulo: Pearson Prentece Hall, 2002.

BRASIL. Ministério da Educação. Parâmetros Curriculares Nacionais: pluralidade cultural e orientação sexual, temas transversais, Secretaria da Educação Fundamental. 3 ed. Brasília: SEF, 2007.

BRASIL. Ministério do Turismo. Turismo cultural: orientações básicas./ Ministério do turismo, Secretaria Nacional de Políticas de Turismo, Departamento de Estruturação, Articulação e Ordenamento Turístico, Coordenação Geral de Segmentação. 2 ed. Brasília: Ministério do Turismo, 2008. Disponível em: <http://www.turismo.gov.br> Acesso em: 22 maio 2010.

COSTA, A.O. Viagem ao universo de Câmara Cascudo: tentativa de ensaio bibliográfico. Natal: EDUFRN, 2008.

DIAS, R Turismo e patrimônio cultural: recursos que acompanham o crescimento das cidades. São Paulo: Saraiva, 2006.

LIMA, D.C. Câmara Cascudo: um brasileiro feliz. 3 ed. Rev. aum. Comemorativa dos 100 anos de nascimento de Luis da Câmara cascudo. Rio de Janeiro: Lidador, 1998.

LYRA, C. (org.). Luís da Câmara Cascudo: depoimento. Natal:EDUFRN, 1999.

LAKATOS, E.M.; MARCONI, M.A. Fundamento da metodologia cientifica. 6 ed. São Paulo: Atlas, 2007.

PIRES, M.J. Lazer e patrimônio cultural. Barueri: Manole, 2001.

SANTANA, A. Antropologia do turismo: analogias, encontros e relações; tradutora Eleonora Frenkel Barretto. São Paulo: Aleph, 2009. 
Patrícia Daliany Araújo do Amaral: Instituto Federal de Educação, Ciência e Tecnologia do Rio Grande do Norte, Natal, RN, Brasil.

Email: pdaliany@hotmail.com

Link para o currículo Lattes: http://lattes.cnpq.br/4172795219000524

\section{Andreia Candida dos Santos}

Email: andreinhanat@hotmail.com

Josineide Silva Monteiro: Instituto Federal de Educação, Ciência e Tecnologia do Rio Grande do Norte, Natal, RN, Brasil.

Email: josineide_s@hotmail.com

\section{Mickaella de Fátima Medeiros}

Email: mickaellafm@hotmail.com

Tatiana Gehlen Marodin: Instituto Federal de Educação, Ciência e Tecnologia do Rio Grande do Norte, Natal, RN, Brasil.

Email: tatianagehlen@hotmail.com

Link para o currículo Lattes: http://lattes.cnpq.br/1670419112826833

Data de submissão: 28 de junho de 2012

Data de recebimento de correções: 17 de agosto de 2012

Data do aceite: 17 de agosto de 2012

Avaliado anonimamente 